\title{
Formação e Prática do Professor de Medicina: um Estudo Realizado na Universidade Federal de Rondônia
}

\author{
Training and Practice of the Medicine Teacher: \\ a Study Performed at the Federal University of \\ Rondônia
}

Chrystiano de Campos Ferreira Ana Maria de Lima Souza ${ }^{I}$

\section{PALAVRAS-CHAVE}

- Educação Superior;

- Educação Médica;

- Docentes.

\section{KEYWORDS}

- Education, Medical;

- Faculty, Medical;

- Teaching.
Recebido em: 29/04/2015

Reencaminhado em: 18/05/2015

Aprovado em: 27/07/2015

\section{RESUMO}

Objetivo: Analisar a formação e prática pedagógica do médico-professor situada no contexto dos cursos de Medicina das três instituições de ensino superior que oferecem a formação médica em Porto Velho (RO), tendo como referência as percepções dos próprios médicos-professores. Métodos: A pesquisa teve abordagem tanto quantitativa quanto qualitativa, sendo composta de duas fases. A primeira foi constituída pela aplicação de um questionário, e a segunda foi efetivada com a realização de entrevistas semiestruturadas. Resultados: O estudo permitiu identificar que os saberes docentes são construídos com as vivências de cada professor e não necessariamente por meio de cursos específicos. Conclusão: Os médicos-professores estão satisfeitos com o seu conhecimento e a experiência adquirida durante os anos de docência. Para os entrevistados, ter uma formação docente específica não é um pré-requisito para ser um "bom" professor de Medicina.

\section{ABSTRACT}

Objective: To analyze the training and teaching practice of medical teachers within the context of medical courses of the three higher education institutions that offer medical training in Porto Velho, with reference to the perceptions of medical teachers themselves. Methods: The study took both a quantitative and qualitative approach, consisting of two phases. The first involved the application of a questionnaire and the second consisted of semi-structured interviews. Results: The study revealed that teachers' knowledge is constructed from the experiences of each professional and not necessarily through specific courses. Conclusion: The medical teachers are satisfied with their knowledge and experience gained through years of teaching. For the interviewees, specific teacher training is not a prerequisite for being a "good" teacher of Medicine. 


\section{INTRODUÇÃO}

O professor da graduação do curso de Medicina, na maioria das vezes, é um médico especialista em determinada área que, após a formação, inicia a atividade docente sem uma base pedagógica $^{1-6}$. Médicos com afinidade pelo ensino começam a ministrar aulas nos cursos de graduação e se tornam professores sem preparo para isto. Ou seja, "aprendem a ensinar ensinando", copiando professores julgados como bons docentes. Nesse sentido, diferentemente dos outros graus de ensino, esse professor se constituiu, historicamente, tendo como base a profissão paralela que exerce ou exercia no mundo do trabalho. A ideia de que quem sabe fazer sabe ensinar deu sustentação à lógica do recrutamento dos docentes ${ }^{7}$.

Vários relatórios focam o tema da educação médica e a formação de novos médicos no Brasil e no mundo, mas nenhum foi mais comentado e referido que o relatório Flexner. Este foi escrito em 1910 por Abraham Flexner, após uma visita a 155 escolas médicas na América do Norte, onde identificou problemas na formação do médico. Sua publicação revolucionou o ensino médico ${ }^{5}$.

Em suas constatações, logo na introdução de seu relatório, Flexner aponta que a formação de médicos mal treinados se devia principalmente à existência de grande número de escolas comerciais, sustentadas em muitos casos por métodos de publicidade por meio dos quais uma massa de jovens despreparados é retirada de ocupações industriais para o estudo da medicina $^{5}$

Os dados constantes desse relatório são tão atuais que, às vezes, é difícil acreditar que foi escrito no século passado, há mais de cem anos. Ele demonstra o quanto os governos não têm se preocupado com a educação de qualidade.

A docência é considerada atividade secundária à profissão médica, e a carreira docente não é tida como profissão ${ }^{2,3,4,8,9}$. Esses professores, de modo geral, são considerados bons profissionais em sua área específica de atuação, e o critério de contratação dos docentes nos cursos médicos é centrado na qualidade de seu desempenho em sua área técnica de atuação ${ }^{4}$.

$\mathrm{Na}$ atualidade, vive-se um movimento pedagógico que tenta substituir o conceito de professor tradicional, acadêmico ou enciclopédico e o do especialista-técnico pelo conceito de professor construtivo, crítico ${ }^{10-14}$.

Esse pensamento encontra eco em Freire ${ }^{15}$, que critica a forma tradicional de ensino, abordando a concepção bancária da educação como instrumento de opressão, na qual o aluno é um depósito para os conhecimentos do professor. Desse modo, ganham realce as questões relativas à profissionalização do professor, encarada como uma das estratégias para repensar a dinâmica da formação em saúde em suas dimensões institucio- nal e social: pensar a docência como profissão influencia toda e qualquer iniciativa de ampliação de vínculo institucional dos professores e de aumento de tempo de dedicação à escola ${ }^{1}$.

Nesse contexto, considerando que a contribuição do professor de medicina é fundamental para a reorientação da educação médica, ampliando as perspectivas de transformação dos cursos, não há como pensar as mudanças dissociadas do docente. Este precisa de apoio institucional para se desenvolver não apenas no que diz respeito ao conhecimento técnico-científico e ao processo de ensino-aprendizagem, mas, sobretudo, no que se refere à gestão do curso médico na própria academia e na interação com os serviços e a comunidade ${ }^{8}$.

Segundo dados do Instituto Nacional de Pesquisas e Estudos Educacionais (Inep), em 2011 havia no Brasil 378.257 professores de ensino superior, sendo que 150.815 trabalhavam na rede pública e 227.442 na rede privada. Deste total de professores, 207.383 eram do sexo masculino, e 170.874, do sexo feminino ${ }^{16}$.

$\mathrm{O}$ objetivo geral desta pesquisa foi analisar a formação e a prática pedagógica do médico-professor situada no contexto dos cursos de Medicina das três instituições de ensino superior que oferecem a formação médica em Porto Velho, uma das capitais da região amazônica, tendo como referência as percepções dos próprios médicos-professores.

\section{MATERIAL E MÉTODOS}

Este estudo foi parte integrante da dissertação de mestrado apresentada ao programa de ensino em ciências da saúde da Universidade Federal de Rondônia.

Realizamos uma pesquisa com abordagem tanto quantitativa quanto qualitativa do tipo estudo de caso.

$\mathrm{O}$ universo em que os dados foram obtidos abarcou três instituições de ensino superior que oferecem a formação médica no município de Porto Velho, capital do Estado de Rondônia: uma instituição pública, a Universidade Federal de Rondônia, e duas particulares. Situada na margem direita do Rio Madeira, na parte oeste da Região Norte, Porto Velho conta com uma população estimada de 484.992 habitantes para o ano de $2013^{17}$.

Critérios de inclusão: professores dos cursos de Medicina da cidade de Porto Velho que tenham graduação em Medicina e que possuam vínculo empregatício com as respectivas instituições.

Critérios de exclusão: foram excluídos os professores que ministram aulas em alguma dessas instituições, porém sem vínculo empregatício, nesse caso, os professores colaboradores.

A pesquisa se realizou em duas fases: a primeira consistiu na aplicação de questionário adaptado de Costa $^{2}$ para levantar informações sobre tempo de docência, qualificação acadêmica, disciplinas ministradas, formação pedagógica e dificuldades do 
início da carreira docente, entre outros aspectos, com o objetivo de traçar o perfil desses professores; a segunda fase constou de uma entrevista em que foram coletadas informações sobre a percepção desses professores quanto a sua formação docente.

Foram enviados questionários para a totalidade dos médicos-professores (127), mas apenas 40 restituíram o instrumento preenchido. A justificativa dos que não enviaram foi falta de tempo para responder.

Para o tratamento dos dados das questões fechadas recolhidos por meio dos questionários utilizamos o programa estatístico Epi Info (versão 6).

Submetemos o projeto ao Comitê de Ética em Pesquisa (CEP) da Universidade Federal de Rondônia, sendo aprovado pelo Parecer no 220.952, de 15 de março de 2013, CAAE 09761512.6.0000.5300 Após sua aprovação, iniciamos a pesquisa de campo. Todos os participantes assinaram o Termo de Consentimento Livre e Esclarecido (TCLE).

\section{RESULTADOS E DISCUSSÃO}

A cidade de Porto Velho tem 127 médicos-professores, que trabalham em três instituições, uma pública e duas privadas.

\section{Gênero}

Dos 40 médicos-professores estudados, 26 (65\%) são do sexo masculino e 14 (35\%) do sexo feminino. Esses dados estão consoantes com o relatório final da Cinaem que conclui que a maioria dos médicos-professores brasileiros era constituída por homens $(67 \%)^{18}$. Esses dados também seguem os dados do censo da educação superior Inep/MEC, segundo os quais, dos 378.257 professores de ensino superior no Brasil no ano de 2011, 207.383 eram do sexo masculino e 170.874 eram do sexo feminino, evidenciando uma maioria de professores do sexo masculino ${ }^{16}$.

\section{Faixa etária}

A idade dos médicos-professores variou de 30 a 69 anos, com predomínio da faixa de 30 a 39 anos (43,2\%). O relatório da Cinaem também aponta a faixa de 30-49 anos como predominante entre os médicos-professores ${ }^{18}$.

\section{Nacionalidade e estado de nascimento}

Em relação à nacionalidade, dos 40 médicos-professores, 37 nasceram no Brasil, um em Bogotá, Colômbia, um em Santa Cruz, Bolívia, e um em Cochabamba, Bolívia. Os estados brasileiros com maior incidência de nascidos foram São Paulo, com 10 (25\%), seguido de Rondônia, com 7 (17,5\%).

Acreditamos que a presença de três estrangeiros, oriundos de países da América do Sul (Colômbia e Bolívia), se deva à proximidade de Porto Velho com a fronteira desses países.

\section{Tempo de formação}

Em relação ao tempo de formado, houve variação entre 5 e 46 anos, com predominância da faixa entre 10 e 19 anos de formado (Gráfico 1). Aqui, destacamos uma singularidade frente à informação constante do relatório final da Cinaem, que aponta que mais da metade dos médicos-professores tem menos de dez anos de docência ${ }^{18}$.

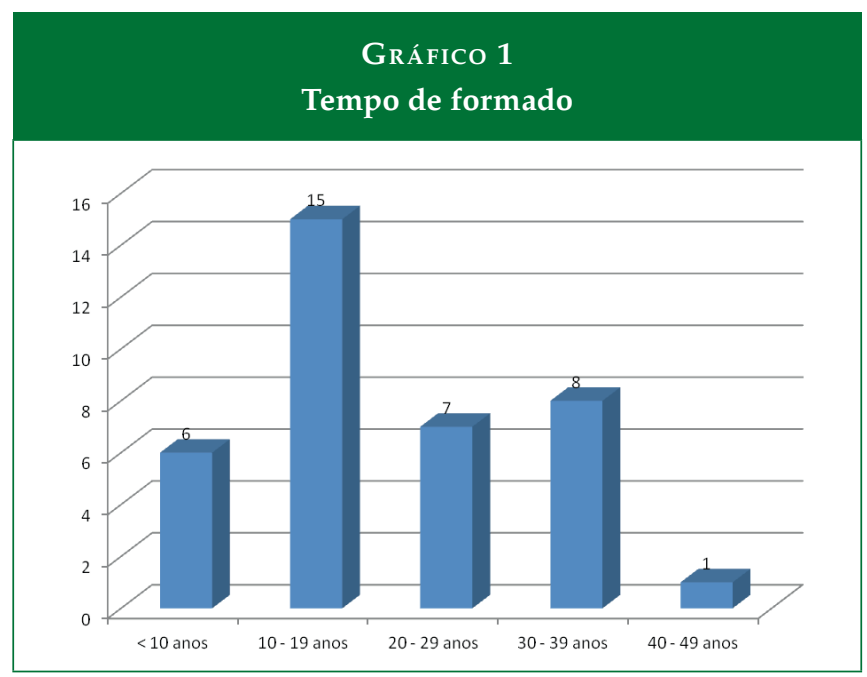

Local de formação

Quando se trata do local, ou seja, do estado onde esses médicos-professores cursaram a graduação em Medicina, destacam-se os estados de São Paulo, com oito (20\%), e do Rio de Janeiro, com igual percentual. Em síntese, como demonstrado no Gráfico 2, 35 dos pesquisados fizeram sua formação médica no Brasil, distribuídos em 14 estados, e cinco em outros países (Bolívia, Argentina, Colômbia e Cuba).

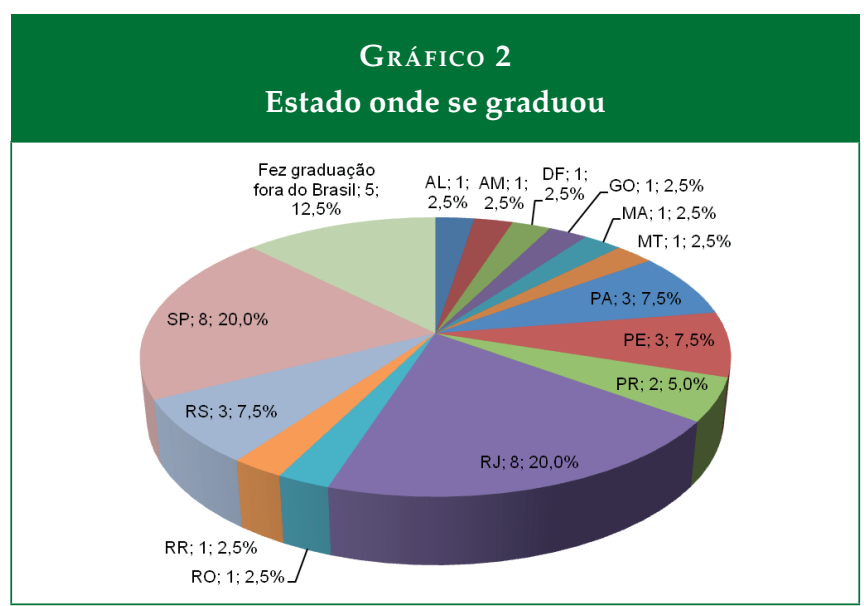




\section{Tempo de atividade como docente}

O tempo de atividade como docente variou de 1 a 43 anos, com média de 6,35 anos de docência, conforme observado no Gráfico 3.

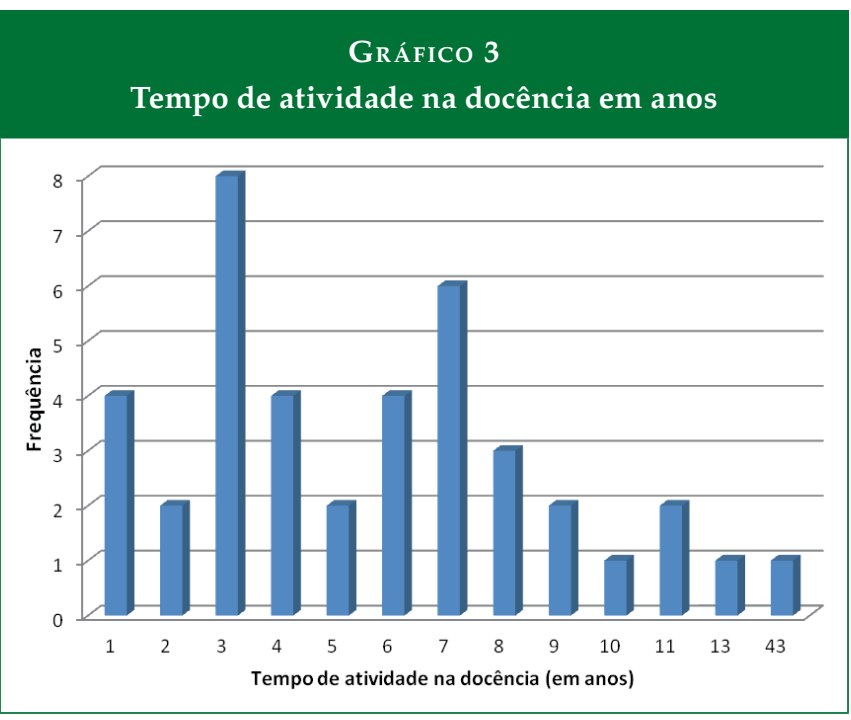

Regime de trabalho

Quanto ao regime de trabalho, 32 médicos-professores afirmam ter contrato parcial de 20 horas; sete estão contratados no regime de 40 horas - tempo integral; e apenas um declarou ter contrato de dedicação exclusiva (DE).

Dados do Cinaem apontam que 22\% dos médicos-professores das IES brasileiras trabalham em regime de dedicação exclusiva, ou seja, a minoria. Os dados desta pesquisa também apresentam reduzido número de médicos dedicados à profissão docente em tempo integral. Entendemos que esta realidade se justifica pelos baixos salários pagos aos professores.

\section{Residência médica}

Trinta e seis (90\%) médicos-professores afirmaram ter cursado ao menos uma residência médica. $\mathrm{O}$ estado brasileiro onde o maior número de médicos realizou residência médica foi São Paulo, com 14 (36\%), seguido do Rio de Janeiro, com 5 (12\%).

\section{Mestrado/doutorado}

Vinte (50\%) dos professores pesquisados têm mestrado e seis (15\%) têm doutorado concluído. Além desses professores, outros sete estão em fase de provável conclusão de mestrado no fim do ano e seis relataram ser alunos de cursos de doutorado. A Tabela 1 apresenta os médicos-professores estudados de acordo com seu maior grau de formação.

\begin{tabular}{|lc|}
\multicolumn{2}{c|}{ TABELA 1} \\
Grau de formação dos docentes pesquisados \\
\hline \multicolumn{1}{|c|}{ Grau de formação } & Número de professores \\
\hline Graduação & 4 \\
Especialização & 10 \\
Mestrado & 20 \\
Doutorado & 6 \\
Total & 40 \\
\hline
\end{tabular}

Grau de formação dos médicos-professores de acordo com a região brasileira da graduação

No decorrer deste trabalho, observamos que os professores se graduaram nas mais diversas regiões brasileiras e também no exterior. Considerando que algumas regiões brasileiras são mais desenvolvidas, como as regiões Sul e Sudeste, comparativamente às regiões Norte e Nordeste, surgiu a seguinte pergunta: será que os médicos-professores graduados nas regiões Sul e Sudeste têm um grau de formação maior do que os que se graduaram nas regiões Norte e Nordeste?

O Gráfico 4 apresenta a distribuição percentual do nível de formação dos médicos-professores que se graduaram nas regiões Norte/Nordeste e Sul/Sudeste, respectivamente. Excluímos do gráfico os médicos-professores que se graduaram no exterior ou na Região Centro-Oeste porque queríamos fazer uma comparação entre as regiões mais desenvolvidas no País (Sul e Sudeste) e as menos desenvolvidas (Norte e Nordeste).

Como se vê, nas regiões Norte/Nordeste, 45,5\% dos médicos-professores têm a residência médica como a sua maior titulação e 18,2\% têm apenas a graduação. Ou seja, 63,7\% ou são apenas graduados em Medicina ou têm residência médica, enquanto nas regiões Sul/Sudeste apenas 33,3\% têm a residência médica como a sua maior titulação e nenhum tem apenas a graduação.

Este dado, revelador da desigualdade educacional estabelecida entre essas regiões, aliado ao fato de que a pós-graduação stricto sensu é a responsável pela produção científica, nos permite inferir que as IES das regiões Sul e Sudeste têm em seus quadros professores com nível de formação mais elevado, atendendo, assim, ao que preceitua o art. 52, inciso II, da LDB, isto é, que um terço do corpo docente, pelo menos, deverá ter titulação acadêmica em nível de mestrado/doutorado.

Comparamos os médicos-professores que se graduaram nas regiões Norte e Nordeste com os que se graduaram nas regiões Sul/Sudeste. Observamos que, nas regiões Norte/Nordeste, $46,5 \%$ dos médicos-professores têm a residência médica como sua maior titulação e 18,2\% têm apenas a graduação. Ou 

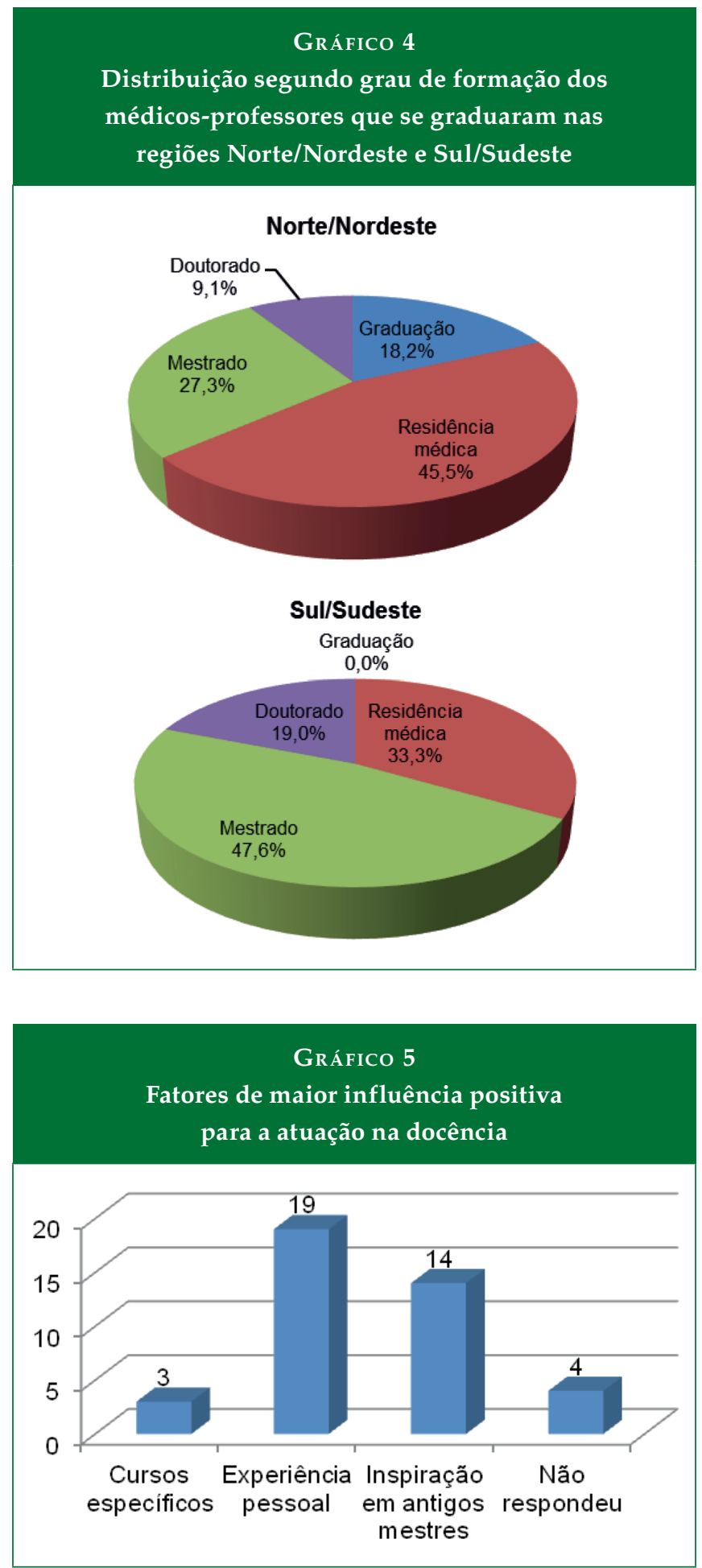

seja, $63,7 \%$ ou são apenas graduados em Medicina ou têm residência médica. Já nas regiões Sul/Sudeste, apenas 33,3\% têm a residência médica como sua maior titulação e nenhum tem apenas a graduação.

\section{A FORMAÇÃO E A PRÁTICA PEDAGÓGICA: A VOZ DOS MÉDICOS-PROFESSORES}

Iniciando a carreira de professor

Foi perguntado qual o fator mais influente para esses profissionais terem se tornado professores. Dos 40 médicos-professores, a maioria $(47,5 \%)$ apontou a experiência pessoal, seguida pela inspiração em antigos mestres (35\%) (Gráfico 5).

\section{Formação docente}

Questionados se tiveram formação na área da educação, 17 $(42,5 \%)$ responderam que sim e $23(57,5 \%)$ responderam não. Nessa resposta, eles citaram as matérias do mestrado ou da especialização que cursaram. Um se referiu à formação didático-pedagógica na área da saúde, um à especialização em ensino médico, um referiu-se ao Curso de Docência - Metodologia do Ensino Superior, três à especialização em Metodologia do Ensino Superior, sete se referiram a disciplinas cursadas no mestrado/doutorado e três mencionaram cursos ou congressos realizados na área da Educação.

Visão dos docentes quanto a sua formação pedagógica

Perguntados como avaliavam a própria formação pedagógica, a maioria dos médicos-professores, $23(57,5 \%)$, considerou satisfatória, 8 (20\%) como boa, $4(10 \%)$ como ótima, 3 (7,5\%) como ruim e 2 (5\%) não responderam (Gráfico 6).

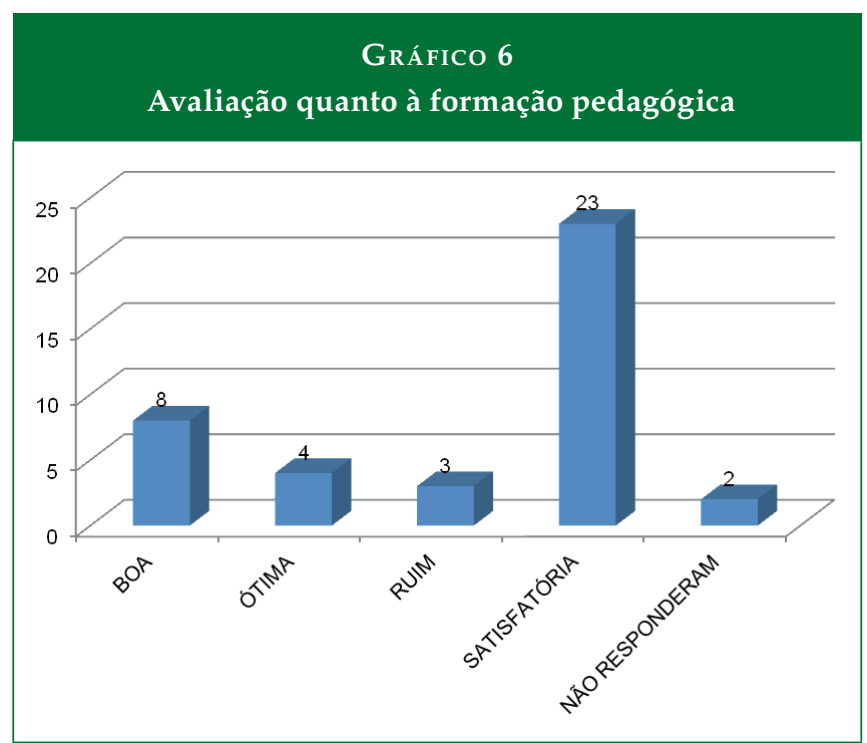

Entendemos que 87,5\% desses médicos-professores estão satisfeitos com sua formação pedagógica, porque têm conseguido dar conta das questões que envolvem a atividade docente, pelo menos no que se refere a ministrar as aulas. 
Embora não tenham uma formação específica, 35 dos 40 consideraram sua formação docente satisfatória, boa ou ótima.

Quatro dos professores deixaram transparecer que, mesmo sem uma formação específica, conseguem "passar" os conhecimentos médicos.

Não tenho formação em docência, porém consigo passar de forma clara e dinâmica os conhecimentos médicos. (MP17)

Acredito que as aulas estejam sendo bem aplicadas de maneira satisfatória. (MP4)

Não tenho formação específica na docência, porém acredito ter o perfil para lecionar, pois consigo ter boa comunicação e relação com alunos e mesmo quando avaliados por outros docentes demonstram bom aprendizado. (MP11)

Observo a evolução educacional dos alunos e tenho recebido críticas favoráveis. (MP12)

Observa-se, aqui, uma visão do ensino como processo de transmissão e assimilação de conteúdos, tudo aquilo que Freire ${ }^{11}$ criticava e considerava como "educação bancária" - os professores passam os conteúdos das aulas aos alunos, que "recebem" passivamente essas aulas como depositários do conhecimento. No entendimento de $\mathrm{Costa}^{3}$, a pouca valorização da formação pedagógica do professor universitário pode ser atribuída ao desmerecimento das atividades de ensino nas universidades, levando os professores ao entendimento de que basta dominar o conhecimento específico para ser professor.

\section{As aulas no início da carreira: dificuldades}

Uma das maiores dificuldades enfrentadas por esses médicos-professores foi a falta de recursos didáticos e metodológicos como os disponíveis na atualidade. Além disso, foi apontado o excesso de informações contidas em suas aulas no início da carreira, ou seja, a dificuldade para definir o quê, como ensinar e avaliar. O tempo também foi lembrado como fator limitante em virtude das diversas atividades exercidas pelo médico-professor, fato que, sem dúvida, compromete seu desempenho didático e pedagógico.

Eis que o desafio se apresenta:

Eu aprendi a dar aula por minha conta, nunca tive uma formação didático-pedagógica. Então, a gente foi trocando experiência como aluno e depois como professor. Porque a gente, como aluno, sentia a dificuldade que determinados professo- res tinham de transmitir o conhecimento. A gente passava também por uma determinada angústia como aluno. Num determinado ponto, acho que tirei algum proveito nesse sentido. (MP15)

Fatos como este revelado por MP15 referendam o mito do "dom" para o exercício do magistério. Todavia, revelam que esse professor se apropriou das experiências tanto como aluno como professor e, num processo de crítica e autocrítica, foi se construindo professor. Por fim, reconhece: “Talvez se eu tivesse tido uma formação pedagógica lá atrás, teria uma desenvoltura melhor hoje".

Masetto $^{14}$ inclui nas competências para o exercício da docência no ensino superior o domínio da área pedagógica e alerta que, para ter esse domínio, esses profissionais devem ter, no mínimo, clareza quanto a quatro eixos desse processo: "o próprio conceito de processo ensino-aprendizagem, o professor como conceptor e gestor do currículo, a compreensão da relação professor-aluno e aluno-aluno no processo, e a teoria e a prática básica da tecnologia educacional" $(p .55)^{14}$, aspectos que foi possível observar nas falas desses pesquisados.

Observamos, ainda, que os saberes docentes são construídos com as vivências de cada professor e não necessariamente por meio de cursos específicos. Além disso, notamos uma satisfação deles com o conhecimento e a experiência adquiridos durante os anos de docência. Nesse sentido, encontramos respaldo em Cunha ${ }^{11}$, que alerta para o fato de que o professor "constrói sua performance a partir de inúmeras referências. Entre elas estão sua história familiar, sua trajetória escolar e acadêmica, sua convivência com o ambiente de trabalho, sua inserção cultural no tempo e no espaço" (p.62) ${ }^{11}$.

\section{Mudanças na prática pedagógica: superando dificuldades}

A superação das dificuldades do início da carreira vai se refletindo em novas práticas, conforme os participantes da pesquisa:

Então, as minhas aulas, no decorrer dos anos, se enxugaram em termos de conteúdo, mas se valorizaram em termos da discussão desses conteúdos, que eu considero mais básicos. (MP14)

Eu acho que melhorou porque hoje eu tenho os slides menos carregados, já com certa intimidade com as aulas que eu dou, que não mudaram muito os temas desde que eu comecei em 2006. E eu posso discursar um pouco mais em cima de cada tema de forma mais tranquila do que no início, quando eu carregava mais os meus slides e tentava passar um conheci- 
mento acima da própria capacidade de que o aluno no nível em que estava teria condições de absorver. (MP14)

Essa fala revela uma nova compreensão a respeito do ensino, que sai de uma ideia de ensino como mera transmissão para uma ideia de que, para ensinar, é necessário eleger conteúdos relevantes e possibilitar que os alunos transitem por eles.

Nota-se que, ao longo dos anos, as aulas desses professores ficaram com um conteúdo mais objetivo, e eles próprios ficaram mais "didáticos", sabendo o que abordar em suas aulas e como discutir esses assuntos. Reconhecem, ainda, a interação e a comunicação como fatores concorrentes para o bom desenvolvimento do processo de ensinar e aprender. Isto nos remete a Cunha ${ }^{11}$, que alerta para o fato de que o professor "constrói sua performance a partir de inúmeras referências. Entre elas estão sua história familiar, sua trajetória escolar e acadêmica, sua convivência com o ambiente de trabalho, sua inserção cultural no tempo e no espaço" (p.67) ${ }^{11}$.

\section{O que os médicos-professores mudariam na sua formação}

Perguntados se sua formação poderia ter sido melhor, 37 docentes responderam que sim $(92 \%), 2(5 \%)$ responderam que não e um (3\%) não respondeu à pergunta. As justificativas são diversas. Alguns docentes apenas referiram que sempre é possível melhorar aquilo que se faz, sem informar o que poderia ser melhorado: "Sempre é possível melhorar nossa atuação como docente" (MP27). Porém, outros fizeram apontamentos significativos, como os seguintes:

Eu mudaria muita coisa. A primeira coisa que eu gostaria de mudar é o meu tempo; segundo, o salário, para eu dedicar mais tempo ainda à profissão que eu estivesse fazendo... (MP38)

Com maior dedicação tudo fica melhor. Se tivesse mais tempo pra realizar uma formação mais adequada, mas ninguém está interessado nisso, só nas cobranças, seja a instituição, seja o Ministério da Educação. Tendo em vista o salário ridículo que é pago para a maior parte dos professores, sugiro aos colegas aprender com os coreanos, esses sim, são sérios. (MP37)

Aqui, buscamos referência em Cunha ${ }^{11}$, para quem provocar o professor para que ele organize narrativas destas referências, ou seja, das experiências, "é fazê-lo viver um processo profundamente pedagógico, onde sua condição existencial é o ponto de partida para a construção de seu desempenho na vida e na profissão". Por meio da narrativa, ele vai descobrin- do os significados que tem atribuído aos fatos que viveu e, assim, vai reconstruindo a compreensão que tem de si mesmo.

Como afirma MP27, para ter mais dedicação ao que se faz, é necessário um salário que possibilite a sobrevivência com dignidade.

Conforme MP37, uma formação mais adequada carece de tempo, porém "ninguém está interessado", nem a própria IES nem o MEC, e radicaliza: "sugiro aos colegas aprender com os coreanos, esses sim, são sérios". Depreende-se desse desabafo indignado que as políticas públicas voltadas para a educação, além de insuficientes, sofrem de falta de seriedade por parte dos que têm de executá-la, seja em nível micro, seja em nível macro.

Um dos pesquisados tem uma visão de que nascemos predestinados:

Eu acho que o médico é médico, ele não nasceu para ser professor. Aqueles que realmente se dedicam à vida acadêmica geralmente não se destacam na vida profissional. E na realidade você tem um tipo de formação que não the permite muito isso. Eu acho que qualquer médico deveria ter algum tipo de preparo antes. Não a gente começar para depois aprender, mas algum pré-requisito ou alguma coisa paralela, que muitas vezes a própria instituição poderia oferecer, um curso de didática, alouma coisa para que esse médico que não tem preparo para a docência fosse mais bem preparado para esse momento. (MP14)

Aqui vemos um paradoxo, pois a contratação do médico para ser professor tem como referência o seu desempenho médico. Por fim, o entrevistado apela para as instituições no sentido de oferecerem ao médico o preparo para entrar em ação de modo que ele já adentre no ofício ao menos com o mínimo preparo. Conforme Perimi ${ }^{8}$, esse docente precisa de apoio institucional para se desenvolver não apenas no que diz respeito ao conhecimento técnico-científico e ao processo de ensino-aprendizagem, mas, sobretudo, no que se refere à gestão do curso médico na própria academia e na interação com os serviços e a comunidade. Por fim, afirmamos que os participantes da pesquisa têm clara a necessidade de qualificação pedagógica.

\section{CONCLUSÃO}

Para os pesquisados, ter ou não uma formação docente específica não é um pré-requisito para ser um "bom" professor de Medicina. Afinal, a docência é atividade secundária e não uma profissão. Por outro lado, o conhecimento técnico da área é imprescindível, segundo alguns professores. Mas reconhe- 
cem que a prática docente exige mais que dar boas aulas, bem como não basta ser médico para ser professor.

Além disso, notamos uma satisfação dos participantes com o conhecimento e a experiência adquiridos nos anos de docência. Isto nos permite concluir que o processo de superação das dificuldades conduz ao melhoramento e à ampliação das habilidades básicas, bem como a construção dos saberes docentes acontece no decurso das atividades, na interação professor-aluno e professor-professor.

Outra variável foi acreditar que haveria maior adesão dos médicos-professores à pesquisa. Foi para mim uma surpresa a não adesão "em massa", como eu esperava. Alguns dos que não responderam ao questionário, ao me encontrar, perguntavam sobre a pesquisa e pediam desculpas por não terem respondido ainda. Outros perguntavam sobre a pesquisa e comentavam sobre a importância de haver um mestrado na área de educação em saúde em nossa região.

Ao longo dos anos, as aulas desses professores ficaram com um conteúdo mais objetivo, e eles próprios ficaram mais "didáticos", sabendo o quê e em que medida ensinar, como abordar os temas e como conduzir a discussão destes. Por conseguinte, os saberes docentes são construídos com as vivências de cada professor, revisando sempre sua prática pedagógica, e não necessariamente por meio de cursos específicos.

Além dos problemas gerais, inerentes a todo curso universitário, não é simples para esse professor entrar em sala de aula sem ter noção sobre a diversidade humana, as diferenças entre os alunos que poderá encontrar em sala de aula, a multiculturalidade e tantas outras questões que na atualidade ganham destaque no cenário do ensino brasileiro, exigindo mais da atividade docente. Esses problemas talvez pudessem ser minimizados com um treinamento específico. Não falo de mestrado ou doutorado, mas, sim, de um curso de formação de curta duração que pudesse antecipar ao jovem professor universitário as adversidades que ele irá encontrar em sala de aula.

Saliento que encerro com mais indagações do que com certezas. Reconheço que este estudo é um embrião com potencial para se desenvolver e, a partir da curiosidade com que aqui chego, continuar a realizar estudos que me possibilitem ampliar e aprofundar mais o conhecimento a respeito de ser médico-professor. Quem sabe, em nível de doutorado.

\section{REFERÊNCIAS}

1. Canuto AM, Batista SH. Concepções do processo ensino-aprendizagem: um estudo com professores de medicina. Rev. bras. educ. med. 2009;33(4):624-632.

2. Costa N. A formação e as práticas educativas de professores de medicina: uma abordagem etnográfica. Tese de doutorado em educação: currículo. Pontifícia Universidade católica de São Paulo; 2005.

3. Costa N. Docência no Ensino Médico: por que É Tão Difícil Mudar? Rev. bras. educ. med. 2007;29(1).

4. Costa N. Formação pedagógica de docentes de medicina. Revista Latino-Americana de Enfermagem (USP. Ribeirão Preto).2010;18:102-108.

5. Flexner, A. Medical Education in the United States and Canada. New York: Carnegie Foundation for The Advancement of Teaching; 1910.

6. Rodriguez CA, Neto PP, Behrens M A. Paradigmas educacionais e a formação médica. Rev. bras. educ. med. 2004;28:234-241.

7. Cunha M. O lugar da formação do professor universitário: o espaço da pós-graduação em educação em questão. Rev. Diálogo Educ. 2009; 9(26):81-90.

8. Perimi G. Desenvolvimento docente e a formação de médicos. Rev. bras. educ. med. 2009;33(1).

9. Rodriguez CA. As inovações no ensino superior e a formação do médico professor.Paraná; 2003. Mestrado [Dissertação] - Pontifícia Universidade Católica do Paraná.

10. Altet M. As competências do professor profissional: entre conhecimentos, esquemas de ação e adaptação, saber analisar. In: Paquay L. Formando professores profissionais: quais estratégias? Quais competências? Porto Alegre: Artmed; 2001.

11. Cunha M. O professor universitário na transição de paradigmas. ${ }^{\underline{a}}$ Ed. Araraquara: Junqueira \& Marin editores; 2005.

12. Imbernón F. Formação docente e profissional. 9. ed. São Paulo: Cortez; 2011.

13. Machado J. A participação da ANDES-SN na CINAEM: o processo de transformação das escolas médicas brasileiras. Revista Interface (Botucatu).1998;3(5).

14. Masetto M. Docência na universidade. Campinas: Papirus; 1998. 112p.

15. Freire P. Pedagogia do oprimido. 50. ed. Rio de Janeiro: Paz e Terra; 2011.

16. Instituto Nacional de Estudos e Pesquisas Educacionais (INEP/MEC). Censo da educação superior 2011, MEC/ Inep/Deaes. Brasília: 2011. Disponível em: <http:/ / portal. inep.gov.br/superior-censosuperior-sinopse >. Acesso em: 02 Jan. 2012.

17. Instituto Brasileiro de Geografia e Estatística. Cidades. Disponível em: http://cidades.ibge.gov.br. Acesso em 08/12/2013

18. Comissão interinstitucional de avaliação do ensino médico. Avaliação das Escolas Médicas Brasileiras - Relatório Geral. Rio de Janeiro: Cinaem; 1997. 


\section{CONTRIBUIÇÃO DOS AUTORES}

Chrystiano de Campos Ferreira: autor do artigo. Ana Maria de Lima Souza: coautora, foi a orientadora do mestrado e deste artigo, que faz parte da dissertação.

\section{CONFLITOS DE INTERESSES}

Não há.

\section{ENDEREÇO PARA CORRESPONDÊNCIA}

Chrystiano de Campos Ferreira

Departamento de Medicina da Universidade Federal de Rondônia - Campus José Ribeiro Filho BR 364, km 9,5, bloco 2C, sala 212 - Porto Velho

CEP 76801-059 - RO

E-mail: Chrystiano_campos@yahoo.com.br 